Jurnal Dinamika Ekonomi dan Bisnis, Vol 17 (02) Oktober 2020, 131-141

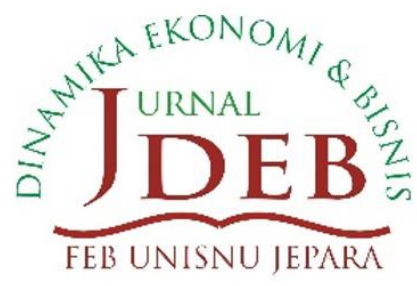

https://ejournal.unisnu.ac.id/JDEB

Terakreditasi Sesuai Kutipan Keputusan Direktur Jenderal Penguatan

Riset dan Pengembangan, Kementerian Riset, Teknologi, dan Pendidikan

Tinggi Republik Indonesia Nomor: 21/E/KPT/2018

\title{
PENGARUH GAYA KEPEMIMPINAN, MOTIVASI, DISIPLIN KERJA TERHADAP KINERJA KARYAWAN PADA PT. HUAWEI TECH INVESTMENT
}

\author{
Jaenudin $^{1)}$, Firlana Whydia Putra ${ }^{2)}$, Fanesya Desilfa ${ }^{3)}$, Iskandar Ahmaddien ${ }^{4)}$ \\ Fakultas Ekonomi Universitas Sangga Buana YPKP Bandung ${ }^{1,2,3)}$, \\ Email : jaennu97@gmail.com ${ }^{1)}$, firlanaputra.fp@gmail.com ${ }^{2)}$, fanesyadesilfa19@gmail.com ${ }^{3)}$, \\ iskandar.ahmaddien@usbypkp.ac.id ${ }^{4)}$
}

\begin{abstract}
This study aims to determine the effect of leadership style, motivation, and work discipline on performance at PT. Huawei Tech Investment. There are negative factors that reduce the performance of employees of PT. Huawei Tech Investment, including decreased employee desire to achieve work performance, lack of timeliness in completing work activities and then decreasing compliance with work rules, influence that comes from their environment, colleagues who also decline in enthusiasm and there are no examples that should be used as a reference in achieving good work performance. This research method uses a quantitative approach method. Data collection techniques by distributing questionnaires directly to employees of PT. Huawei Tech Investment uses google form with a sample of 50 people. Using descriptive analysis methods and SEM (Structural Equetion Modeling) research methods with PLS (Partial Least Square) analysis with the help of PLS 2.0 software. Based on the results of the analysis of the factors that significantly influence employee performance are motivation and work discipline because it is proven in hypothesis testing with $t$-statistics greater than t-table, while leadership style does not significantly affect employee performance.
\end{abstract}

Keywords: Leadership Style, Motivation, Work Discipline, and Employee Performance

Abstrak

Penelitian ini bertujuan untuk mengetahui pengaruh gaya kepemimpinan, motivasi, dan disiplin kerja terhadap kinerja pada PT. Huawei Tech Investment. Terdapat faktor negatif yang menurunkan kinerja karyawan PT. Huawei Tech Investment, diantaranya adalah menurunnya keinginan karyawan untuk mencapai prestasi kerja, kurangnya ketepatan waktu dalam penyelesaian aktivitas kerja lalu menurunya ketaatan aturan dalam bekerja, pengaruh yang berasal dari lingkungannya, teman sekerja yang juga menurun semangatnya dan tidak adanya contoh yang harus dijadikan acuan dalam pencapaian prestasi kerja yang baik. Metode penelitian ini menggunakan metode pendekatan kuantitatif. Teknik pengumpulan data dengan membagikan langsung kuesioner kepada karyawan PT. Huawei Tech Investment menggunkan google form dengan sampel 50 orang. Menggunkan metode analisis deskripsi dan metode penelitian SEM (Structural Equetion Modeling) dengan analisis PLS ( Partial Least Square) bantuan software PLS 2.0. Berdasarkan hasil dari analisis faktor yang menpengaruhi kinerja karyawan secara signifikan adalah motivasi dan disiplin kerja karena di buktikan dalam uji hipotesis dengan t-statistik lebih besar dari t-tabel, sedangkan gaya kepemimpinan tidak mempengaruhi signifikan terhadap kinerja karyawan.

Kata Kunci : Gaya Kepemimpinan, Motivasi, Disiplin Kerja, dan Kinerja Karyawan

Sitasi: Jaenudin, Putra, F.W., Desilfa, F., \& Ahmaddien, I. (2020). Pengaruh Gaya Kepemimpinan, Motivasi, Disiplin Kerja Terhadap Kinerja Karyawan Pada PT. Huawei Tech Investment. Jurnal Dinamika Ekonomi dan Bisnis, 17 (02) 2020, 131-141. 


\section{PENDAHULUAN}

Pada berbagai bidang khususnya di dalam sebuah organisasi atau perusahaan tingkat keberhasilan seorang pegawai di nilai dari kinerjanya. Dimana Kinerja seorang pegawai itu berhasil jika seorang pegawai tersebut mencapai prestasi dan mampu melaksanakan tugas serta tanggung jawab yang berikan kepadanya (Kirana dan Ratnasari, 2017). Keberjalanannya suatu organisasi atau perusahaan tidak terlepas dari proses evaluasi yang merupakan fungsi yang sangat penting dilakukan oleh sebuah organisasi atau perusahaan untuk menilai kegiatan kinerja karyawan agar tidak terjadi tindakan yang menyimpang terhadap penilaian kinerja karyawan (Jurnal Manajemen, 2020). Menurut Rotinsulu and Hartono (2015) Kinerja karyawan merupakan faktor penting dalam sebuah perusahaan, karena kinerja karyawan bisa menentukan baik atau tidaknya suatu perusahaan.

PT. Huawei Tech Investment merupakan perusahaan yang bergerak di bidang peralatan dan pelayanan jaringan dan telekomunikasi yang memiliki kantor pusat di Shenzhen, Guangdong. Perusahaan ini didirikan pada tahun 1987 oleh Ren Zhengfei, seorang mantan engineer dari People's Liberation Army. Awalnya Huawei hanya fokus pada produksi phone switches, yang kemudian berkembang menjadi bisnis pembuatan jaringan telekomunikasi yang menyediakan tidak hanya peralatan, namun juga jasa pelayanan domestik maupun di luar Tiongkok. Produk dan pelayanan Huawei kini telah berkembang ke lebih dari 140 negara dan melayani 35 operator telekomunikasi teratas di dunia (Alumni, 2018). Oleh karena itu kinerja karyawan yang tinggi sangatlah di harapkan oleh perusahaan tersebut. Semakin banyak karyawan yang mempunyai kinerja tinggi, maka produktivitas perusahaan secara keseluruhan akan meningkat, sehingga perusahaan dapat bertahan dalam persaingan global.

Kinerja karyawan PT. Huawei Tech Investment juga dapat diukur melalui penyelesaian tugasnya secara efektif dan efisien serta melakukan peran dan fungsinya. Terdapat faktor negatif yang menurunkan kinerja karyawan PT. Huawei Tech Investment, yaitu penurunannya seorang karyawan dalam mencapai prestasi kerja, kurang tepatnya waktu dalam menyelesaikan aktivitas bekerja lalu menurunnya ketaatan aturan dalam bekerja, juga pengaruh negatif dari lingkungannya sosial, teman bekerja yang turunnya semangat berkerja dan tidak ada contoh yang dijadikan acuan dalam pencapaian prestasi kerja yang baik. Semua itu merupakan sebab menurunya kinerja karyawan dalam bekerja. Faktor-faktor yang dapat digunakan untuk meningkatkan kinerja diantaranya adalah gaya kepemimpinan, motivasi dan disiplin kerja (Nisyak, 2018).

Gaya kepemimpinan adalah perilaku yang di pergunakan oleh seorang pemimpin untuk mempengaruhi pikiran, perasaan, sikap, dan perilaku kepada anggota organisasi atau pegawai perusahaan (Mubin and Masruri, 2020). Gaya kepemimpinan yang di terapkan oleh seorang pimpinan memiliki sifat dan perilaku berbeda dalam mempengaruhi anggotanya, karena pemimpin dengan gaya kepemimpinan baik selalu menciptakan motivasi yang tinggi kepada setiap anggotanya sehingga motivasi tersebut menimbulkan semangat kerja serta meningkatkan mutu kinerja anggotanya (Fahmi, 2009). Gaya kepemimpinan yang tepat dalam memimpin suatu perusahaan atau organisasi harus dapat menimbulkan suatu motivasi bagi seorang karyawan atau bawahan untuk berprestasi (Reza dan Dirgantara, 2010).

Menurut Naranjo (2014) untuk memperkuat komitmen dalam sebuah organisasi atau perusahaan dalam mencapai kinerja yang maksimal selain memperhatikan kepemimpinan 
yang diterapkan oleh seorang pemimpin, perlu juga melihat faktor motivasi yang diberikan kepada karyawan atau bawahannya. Motivasi merupakan suatu dorongan yang mempengaruhi psikologis diri seseorang baik dari internal maupun eksternal yang diindikasikan dengan adanya keinginan, kebutuhan, harapan atau cita-cita, serta penghargaan dan penghormatan (Yulianita, 2017). Menurut Abraham Maslow dalam Indriyati (2017) teori motivasi tersusun dalam bentuk hierarki, yaitu ada lima jenjang kebutuhan akan motivasi, meningkat dari tingkat yang lebih rendah ke tingkat yang lebih tinggi diantaranya, yaitu:

1. Kebutuhan Fisiologi atau kebutuhan dasar, yaitu kebutuhan akan jasmani dan rohani

2. Kebutuhan keamanan, yaitu kebutuhan terhadap pelindungan diri dari ancaman yang merugikan fisik ataupun emosional

3. Kebutuhan sosial, yaitu kebutuhan akan rasa dimiliki dan di cintai serta kasih saying

4. Kebutuhan Penghargaan, yaitu respek dengan menilai diri baik oleh orang lain misalnya status, pengakuan dan perhatian

5. Kebutuhan aktualisasi, yaitu dorongan seseorang sesuai ambisinya yang mencakup pertumbuhan, pencapaian potensi, dan pemenuhan kebutuhan diri.

Tidak hanya faktor motivasi tetapi kinerja karyawan juga di lihat dari perilaku seorang karyawan dalam disiplin kerja. Disiplin kerja adalah sebuah sikap akan kesediaan seorang karyawan dalam menaati peraturan yang telah di tetapkan oleh sebuah perusahaan, peraturan tersebut diharapkan agar tenaga kerja dalam sebuah perusahaan menjalankan tugasnya dengan teliti, tertib dan lancer serta karyawan tidak melakukan perbuatan yang menyimpan (Setiawan, 2013). Maka dengan demikian peneliti bertujuan untuk mengetahui pengaruh gaya kepemimpinan, motivasi, dan disiplin kerja terhadap kinerja karyawan pada PT. Huawei Tech Investment.

\section{METODOLOGI}

Metode penelitian ini menggunakan metode pendekatan kuantitatif, yaitu untuk menguji teori objektif yang diperiksa antar variabel (Delfanti et al., 2018). Dengan data primer dan teknik pengumpulan data dengan membagikan langsung kuesioner kepada setiap karyawan PT. Huawei Tech Investment menggunakan google form dengan sampel 50 orang dari seluruh populasi karyawan PT. Huawei Tech Investment. Dengan skala penilaian dari setiap pertanyaan terdapat lima jawaban skor sebagai berikut:

\section{Tabel 1.1 Skala Penilaian}

\begin{tabular}{lc}
\hline \multicolumn{1}{c}{ Jawaban } & Nilai \\
\hline Sangat Baik & 5 \\
Baik & 4 \\
Kurang Baik & 3 \\
Tidak Baik & 2 \\
Sangat Tidak Baik & 1 \\
\hline
\end{tabular}

Dengan pernyataan kuesioner variabel gaya kepemimpinan, motivasi, disiplin kerja, dan kinerja karyawan. Menggunakan metode analisis deskripsi dan metode penelitian SEM (Structural Equetion Modeling) dengan analisis PLS ( Partial Least Square) bantuan software PLS 2.0. Model ditentukan melalui drag \& drop dengan menggambar model 
struktural untuk variabel laten dan dengan menetapkan indikator ke variabel laten (Farre Sostres, 1974).

\section{HASIL}

\section{Analisis Deskripsi}

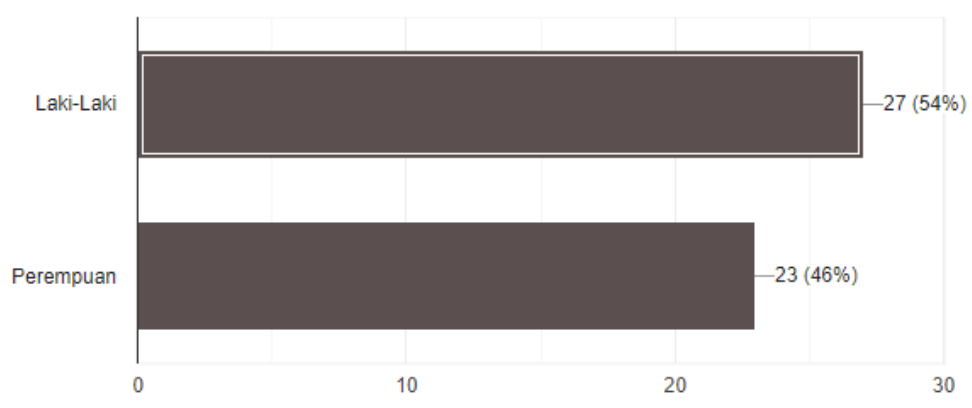

Sumber: Google Form (2020)

\section{Gambar 1.1. Grafik Jenis Kelamin Responden PT. Huawei Tech Investment}

Pada gambar 1.1. Terlihat bahwa jumlah responden dengan jenis kelamin laki-laki mendominasi dalam pengisian kuesioner dibandingkan dengan jenis kelamin perempuan dengan persentase 54\%:46\%.

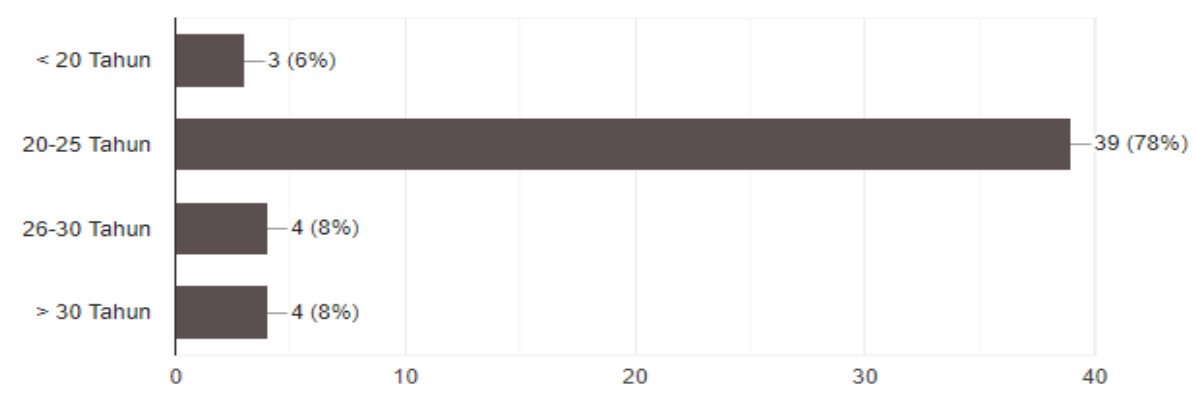

Sumber: Google Form (2020)

\section{Gambar 1.2 Grafik Usia Responden PT. Huawei Tech Investment}

Pada gambar 1.2 dari skala usia < 20 tahun sampai dengan usia > 30 tahun. Didapatkan hasil bahwa usia 20 sampai dengan 25 tahun mendominasi pengisian kuesioner tersebut dengan persentase sebesar $78 \%$ dari total $100 \%$ responden.

\section{Outer Model}

\section{Uji Validitas Konvergen}

Uji validitas konvergen dengan melihat rule of thumb nilai outer loading $>0,7$; Average variance extracted $(\mathrm{AVE})>0,5$; dan Communality $>0,05$, hasil sebagai berikut: 
Tabel 1.2 Outer Loadings

\begin{tabular}{cccccc}
\hline Indikator & $\begin{array}{c}\text { Disiplin } \\
\text { Kerja }\end{array}$ & $\begin{array}{c}\text { Gaya } \\
\text { Kepemimpinan }\end{array}$ & $\begin{array}{c}\text { Kinerja } \\
\text { Karyawan }\end{array}$ & Motivasi & Keterangan \\
\hline X1.1 & & 0,774765 & & & Valid \\
X1.2 & & 0,773660 & & Valid \\
X1.3 & & 0,808257 & & & Valid \\
X1.5 & 0,869844 & & & Valid \\
\hline X2.1 & & & 0,760505 & Valid \\
X2.2 & & & 0,758498 & Valid \\
X2.3 & & & 0,826375 & Valid \\
X2.4 & & 0,863593 & Valid \\
X2.5 & & & 0,786479 & Valid \\
\hline X3.1 & 0,910519 & & & & Valid \\
X3.2 & 0,860301 & & & & Valid \\
X3.5 & 0,832895 & & 0,818242 & & Valid \\
\hline Y.1 & & 0,772751 & & Valid \\
Y.2 & & 0,911122 & & Valid \\
Y.3 & & 0,800982 & & Valid \\
Y.4 & & 0,900991 & & Valid \\
Y.5 & & & & Valid \\
\hline Sumber: Data diolah Software SmartPLS 2.0,2020 & &
\end{tabular}

Tabel 1.3 Average Variance Extracted (AVE) dan Communality

\begin{tabular}{lccc}
\hline \multicolumn{1}{c}{ Indikator } & AVE & Communality & Keterangan \\
\hline Disiplin Kerja & 0.754292 & 0.754292 & Valid \\
Gaya Kepemimpinan & 0.652180 & 0.652180 & Valid \\
Kinerja Karyawan & 0.710033 & 0.710033 & Valid \\
Motivasi & 0.640185 & 0.640185 & Valid \\
\hline
\end{tabular}

Sumber: Data diolah Software SmartPLS 2.0, 2020

Pada tabel 1.2 dan 1.3 menunjukan bahwa nilai outer loadings > 0,7 serta nilai average variance extracted (AVE) dan Communality $>0,05$. Maka dapat disimpulkan bahwa sudah memenuhi uji validitas convergen.

\section{Uji Validitas Diskriminan}

Uji validitas diskriminan dengan melihat rule of thumb nilai cross loadings. 
Tabel 1.4 Cross Loadings

\begin{tabular}{l|cccc|c}
\hline Indikator & $\begin{array}{c}\text { Disiplin } \\
\text { Kerja }\end{array}$ & $\begin{array}{c}\text { Gaya } \\
\text { Kepemimpinan }\end{array}$ & $\begin{array}{c}\text { Kinerja } \\
\text { Karyawan }\end{array}$ & Motivasi & Keterangan \\
\hline X1.1 & 0,433573 & 0,774765 & 0,209701 & 0,591935 & Valid \\
X1.2 & 0,488004 & 0,773660 & 0,319596 & 0,659074 & Valid \\
X1.3 & 0,487507 & 0,808257 & 0,526379 & 0,331935 & Valid \\
X1.5 & 0,637110 & 0,869844 & 0,490321 & 0,515417 & Valid \\
X2.1 & 0,269978 & 0,305581 & 0,098369 & 0,760505 & Valid \\
X2.2 & 0,317615 & 0,262472 & 0,187523 & 0,758498 & Valid \\
X2.3 & 0,315282 & 0,576877 & 0,362368 & 0,826375 & Valid \\
X2.4 & 0,341599 & 0,462796 & 0,465363 & 0,863593 & Valid \\
X2.5 & 0,512629 & 0,601507 & 0,404557 & 0,786479 & Valid \\
X3.1 & 0,910519 & 0,572575 & 0,545507 & 0,420726 & Valid \\
X3.2 & 0,860301 & 0,507032 & 0,581405 & 0,315322 & Valid \\
X3.5 & 0,832895 & 0,596891 & 0,643617 & 0,450139 & Valid \\
Y.1 & 0,507234 & 0,423699 & 0,818242 & 0,286822 & Valid \\
Y.2 & 0,545912 & 0,367566 & 0,772751 & 0,307397 & Valid \\
Y.3 & 0,669652 & 0,551664 & 0,911122 & 0,487411 & Valid \\
Y.4 & 0,451021 & 0,258400 & 0,800982 & 0,295896 & Valid \\
Y.5 & 0,661518 & 0,543548 & 0,900991 & 0,461831 & Valid \\
\hline Sum
\end{tabular}

Sumber: Data diolah Software SmartPLS 2.0, 2020

Dilihat dari tabel 1.4 menunjukan bahwa nilai cross loadings > 0,7. Maka dapat disimpulkan bahwa sudah memenuhi uji validitas diskriminan.

\section{Uji Reliability}

Uji reliability digunakan untuk menguji kekonsistenan item pertanyaan dari setiap indikator dalam kuesioner (Batam, 2018). Uji reliability dengan melihat rule of thumb nilai Cronbach's Alpha > 0,6 dan Composite Reliability > 0,7.

Tabel 1.5 Cronbach's Alpha

\begin{tabular}{lcc}
\hline \multicolumn{1}{c}{ Indikator } & Cronbachs Alpha & Keterangan \\
\hline Disiplin Kerja & 0,836790 & Realibel \\
Gaya Kepemimpinan & 0,832671 & Realibel \\
Kinerja Karyawan & 0,897684 & Realibel \\
Motivasi & 0,871573 & Realibel \\
\hline Sumber: Data diolah Software SmartPLS 20, 2020 &
\end{tabular}


Tabel 1.6 Composite Reliability

\begin{tabular}{lcc}
\hline \multicolumn{1}{c}{ Indikator } & Composite Reliability & Keterangan \\
\hline Disiplin Kerja & 0,901932 & Realibel \\
Gaya Kepemimpinan & 0,882112 & Realibel \\
Kinerja Karyawan & 0,924188 & Realibel \\
Motivasi & 0,898716 & Realibel \\
\hline
\end{tabular}

Sumber: Data diolah Software SmartPLS 2.0, 2020

Pada tabel 1.5 dan 1.6 menunjukan bahwa nilai Cronbach's Alpha > 0,6 dan Composite Reliability > 0,7. Maka dapat disimpulkan bahwa semua item-item dari kuesioner adalah reliable.

\section{Inner Model}

Uji Determinasi (R square)

Tabel 1.7 Nilai R2 Valiabel Endogen

\begin{tabular}{lc}
\hline \multicolumn{1}{c}{ Indikator } & R-Square \\
\hline Disiplin Kerja & \\
Gaya Kepemimpinan & \\
Kinerja Karyawan & 0,494431 \\
Motivasi & \\
\hline Sumber: Data diolah Software SmartPLS 2.0, 2020
\end{tabular}

Dari tabel 1.7 menunjukan bahwa nilai R2 sebesar 0,4944. Maka dapat disimpulkan bahwa konstruk yang dapat di interprestasikan oleh variabel gaya kepemimpinan, motivasi, dan disiplin kerja terhadap kinerja karyawan dengan dijelaskan oleh variabel gaya kepemimpinan, motivasi, dan disiplin kerja sebesar 49,44\% dan sisanya dijelaskan oleh variabel lain yang diluar penelitian ini.

\section{Uji Hipotesis}

Tabel 1.8 Hasil Uji Hipotesis

\begin{tabular}{lcc}
\hline \multicolumn{1}{c}{ Indikator } & $\begin{array}{c}\text { Original } \\
\text { Sample }(\mathbf{O})\end{array}$ & $\begin{array}{c}\text { T Statistics } \\
(\mid \mathbf{O} / \mathbf{S T E R R})\end{array}$ \\
\hline Disiplin Kerja -> Kinerja Karyawan & 0,575432 & $3,909,164$ \\
Gaya Kepemimpinan -> Kinerja Karyawan & 0,065126 & 0,414629 \\
Motivasi -> Kinerja Karyawan & 0,146876 & 2,034523 \\
\hline
\end{tabular}

Sumber: Data diolah Software SmartPLS 2.0, 2020

Berdasarkan tabel 1.8 menunjukan bahwa nilai t-statistik variable Gaya Kepemimpinan terhadap Kinerja Karyawan sebesar 0,414629 dengan nilai original sampel positif sebesar 0.065126, Motivasi Kerja terhadap Kinerja Karyawan sebesar 2,034523 dengan nilai original sampel positif sebesar 0,146876, dan Disiplin Kerja terhadap Kinerja Karyawan sebesar 3,909.164 dengan nilai original sampel positif sebesar 0,575432 serta diperoleh t-tabel sebesar 1,697, maka dapat disimpulkan bahwa gaya kepemimpinan 
mempengaruhi arah positif kinerja karyawan PT. Huawei Tech Investment namun tidak secara signifikan. Kemudian motivasi mempengaruhi kinerja arah positif karyawan PT. Huawei Tech Investment secara signifikan. Sedangkan disiplin Kerja mempengaruhi arah positif kinerja karyawan PT. Huawei Tech Investment secara signifikan.

\section{PEMBAHASAN}

\section{Pengaruh Gaya Kepemimpinan Terhadap Kinerja Karyawan}

Gaya kepemimpinan mempengaruhi arah positif kinerja karyawan PT. Huawei Tech dengan nilai original sampel positif sebesar 0.065126 tetapi tidak berpengaruh secara signifikan karena nilai t-statistik variable Gaya Kepemimpinan terhadap Kinerja Karyawan sebesar 0,414629 lebih kecil dari t-tabel sebesar 1,697.

Berdasarkan hasil penelitian ini menurut S. L. Ratnasari et al.(2019) "The Performance of Sharia Banks Employees X Branch Batam Through Work Motivation" Kinerja Karyawan Bank Syariah X Cabang Batam Melalui Motivasi Kerja" yaitu menunjukkan bahwa disiplin kerja dan kompensasi berpengaruh kinerja karyawan, tetapi gaya kepemimpinan tidak berdampak pada kinerja. Sejalan itu menurut Fatma et al. (2020) Pengaruh Gaya Kepemimpinan, Disiplin Kerja Dan Motivasi Terhadap Kinerja Pegawai Pada Dinas Perdagangan Dan Perindustrian Kabupaten Gowa membuktikan bahwa hasil penelitian variabel gaya kepemimpinan tidak berpengaruh signifikan terhadap kinerja karyawan. Dikarenakan seorang pimpinan memiliki gaya kepemimpinan yang berbeda-beda pada setiap situasi dan kondisi.

Menurut penelitian Ufua et al. (2020) "Addressing operational complexities through re-inventing leadership style: A systemic leadership intervention", yaitu meneliti praktek kepemimpinan di sebuah organisasi studi kasus pada peternakan komersial di Nigeria, menemukan bahwa kesulitan mempertahankan penerapan gaya kepemimpinan tertentu karena sifat kompleksitas yang tidak terstruktur yang terlibat dalam penentuan gaya kepemimpinan. Dikarenakan sifat dari permasalahan yang kompleks yang dihadapi oleh pimpinan dalam suatu proses operasional. Disadari bahwa penerapan gaya kepemimpinan tertentu dapat menjadi tantangan dalam jangka panjang.

\section{Pengaruh Motivasi Terhadap Kinerja Karyawan}

Motivasi mempengaruhi kinerja arah positif karyawan PT. Huawei Tech Investment dengan nilai original sampel positif sebesar 0,146876 dan berpengaruh secara signifikan variabel Motivasi terhadap kinerja karyawan nilai t-statistik sebesar 2,034523 lebih besar dari t-tabel sebesar 1,697.

Berdasarkan hasil penelitian ini sesuai dengan penelitian terdahulu menurut Hersona et al.(2017) "Influence Of Leadership Function, Motivation And Work Discipline On Employees' Performance”, yaitu menganalisa pengaruh fungsi kepemimpinan, motivasi dan disiplin kerja terhadap kinerja karyawan Dinas Tenaga Kerja dan Transmigrasi Kabupaten Karawang membuktikan bahwa motivasi berpengaruh positif dan signifikan terhadap kinerja pegawai. Maka motivasi kerja yang baik memberikan peran penting dalam mendukung kinerja karyawannya, jika karyawan merasa puas dengan sarana dan prasarana yang mendukung pekerjaannya dapat terpenuhi serta pengaruh lingkungan social yang positif juga akan mempengaruhi pencapaian dalam bekerja. 
Menurut Indriyati (2017) Pengaruh Pelatihan Dan Motivasi Terhadap Kinerja Karyawan Dengan Disiplin Sebagai Variabel Intervening (Studi Kasus Di Fakultas Ekonomi Universitas Islam Indonesia) bahwa terdapat pengaruh secara signifikan disiplin kerja terhadap kinerja karyawan tidak terbukti kebenarannya. Penelitian ini sejalan dengan hasil menurut Fatma et al.(2020) Pengaruh Gaya Kepemimpinan, Disiplin Kerja Dan Motivasi Terhadap Kinerja Pegawai Pada Dinas Perdagangan Dan Perindustrian Kabupaten Gowa membuktikan bahwa hasil penelitian variabel motivasi berpengaruh signifikan terhadap kinerja karyawan terbukti kebenarannya, karena motivasi merupakan pendorong produktivitas kinerja seorang karyawan.

\section{Pengaruh Disiplin Kerja Terhadap Karyawan}

Disiplin Kerja mempengaruhi kinerja arah positif karyawan PT. Huawei Tech Investment dengan nilai original sampel positif sebesar 0.575432 dan berpengaruh secara signifikan variabel Disiplin terhadap kinerja karyawan nilai t-statistik sebesar 3.909.164 lebih besar dari t-tabel sebesar 1,697.

Berdasarkan hasil penelitian ini sesuai dengan penelitian terdahulu menurut Hermina dan Yosepha (2019) "The Model of Employe Performance", yaitu Model Kinerja Karyawan Pada PT. Takarindo Utama Pontianak Pengaruh Gaya Kepemimpinan, Motivasi, disiplin Kerja Karyawan bahwa pengaruh gaya kepemimpinan, motivasi dan disiplin kerja berpengaruh signifikan terhadap kinerja karyawan, tetapi secara parsial hanya disiplin kerja yang berpengaruh positif dan signifikan terhadap kinerja karyawan,

Sejalan itu menurut Delfanti et al. (2018) dengan Pengaruh Pelatihan Dan Motivasi Terhadap Kinerja Karyawan Dengan Disiplin Sebagai Variabel Intervening (Studi Kasus Di Fakultas Ekonomi Universitas Islam Indonesia) bahwa terdapat pengaruh secara signifikan disiplin kerja terhadap kinerja karyawan terbukti kebenarannya. Karena disiplin kerja merupakan sikap seorang karyawan untuk menaati sebuah peraturan yang di keluarkan oleh sebuah instansi atau perusahaan agar tidak terjadi sikap yang menyimpang sehingga merugikan perusahaan dan juga pada dirinya.

\section{KESIMPULAN DAN SARAN}

Berdasarkan hasil penelitian ini penulis dapat menyimpulkan bahwa Gaya kepemimpinan pada perusahaan PT. Huawei Tech Investment tidak berpengaruh terhadap kinerja karyawan, dikarenakan setiap pemimpin memiliki sikap dan sifat yang berbeda-beda pada setiap kondisi dan permasalahan yang dihadapi.

Sedangkan motivasi dan disiplin kerja berpengaruh terhadap kinerja karyawan pada PT. Huawei Tech Investment karena dengan motivasi akan menimbulkan pengaruh besar dalam menciptakan tumbuhnya produktivitas seorang karyawan dengan memberikan kenyamanan dan kebutuhan baik secara material maupun nonmaterial seperti pemberian penghargaan atas hasil kerja yang dicapainya. Serta disiplin dalam bekerja seorang karyawan perusahaan harus menaati peraturan yang keluarkan oleh sebuah perusahaan demi kelancaran serta efektivitas dan efisiensi dalam menyelesaikan pekerjaan serta terhindar dari sikap yang menyimpang, merugikan perusahaan dan diri seorang karyawan.

Berdasarkan kesimpulan diatas terdapat gaya kepemimpinan yang tidak berpengaruh terhadap kinerja karyawan, maka pimpinan PT. Huawei Investment Tech diharapkan dapat 
melaksanakan model gaya kepemimpinan yang sesuai sikap dan sifat serta situasi dan kondisi permasalahan yang dihadapi karyawan. Serta motivasi dan disiplin kerja juga harus tetap di tingkat lagi karena demi peningkatan kinerja karyawan pada PT. Huawei Investment Tech menjadi lebih baik lagi.

\section{DAFTAR PUSTAKA}

Alumni, A. (2018). PT Huawei Tech Investment. Available at https://cdc.ittelkompwt.ac.id/pt-huawei-tech-investment-full-time/

Batam, J. (2018). Pengaruh Gaya Kepemimpinan Dan Motivasi Terhadap Kinerja Pegawai Dinas Pemuda Dan Olahraga Kota Pematangsiantar. Jurnal Ilmiah Manajemen Universitas Putera Batam, 6(1), 231180.

Delfanti, R. L., Piccioni, D. E., Handwerker, J., Bahrami, N., Krishnan, A. P., Karunamuni, R., Hattangadi-Gluth, J. A., Seibert, T. M., Srikant, A., Jones, K. A., Snyder, V. S., Dale, A. M., White, N. S., McDonald, C. R., Farid, N., Louis, D. N., Perry, A., Reifenberger, G., von Deimling, A., ... Papers, G. (2018). Pengaruh Pelatihan Dan Motivasi Terhadap Kinerja Karyawan Dengan Disiplin Sebagai Variabel Intervening (Studi Kasus Di Fakultas Ekonomi Universitas Islam Indonesia). New England Journal of Medicine, 372(2), 2499-2508. https://doi.org/10.1056/nejmoa1407279

Yulianita, Arini (2017). Pengaruh Gaya Kepemimpinan Dan Motivasi Terhadap Kinerja Karyawan Cv. Cipta Nusa Sidoarjo. Skripsi. Bachelor Programme. Sidoarjo:Universitas Muhammadiyah Sidoarjo.

Fahmi, S. (2009). Analisis Pengaruh Gaya Kepemimpinan Dan Motivasi Kerja Terhadap Kinerja Pegawai Spbu Pandanaran Semarang. Skripsi. Bachelor Programme. Jakarta: Universitas Gunadarma.

Farre Sostres, J. (1974). Hipoacusias Infantiles Intensas De Frecuencias Altas. Anales Otorrinolaringologicos Ibero-Americanos, 1(5), 70-73.

Fatma, N., Finatry, I., Hardiyono, \& Furwanti, R. (2020). Pengaruh Gaya Kepemimpinan, Disiplin Kerja Dan Motivasi Terhadap Kinerja Pegawai Pada Dinas Perdagangan Dan Perindustrian Kabupaten Gowa. Jurnal GeoEkonomi ISSN-Elektronik, 11(1), 90-101.

Hermina, U. N., \& Yosepha, S. Y. (2019). The Model Of Employee Performance. International Review of Management and Marketing, 9(3), 69-73. https://doi.org/10.32479/irmm.8025

Hersona, S., \& Sidharta, I. (2017). Influence of Leadership Function, Motivation and Work Discipline on Employees' Performance. Jurnal Aplikasi Manajemen, 15(3), 528-537. https://doi.org/10.21776/ub.jam.2017.015.03.18

Indriyati, I. S. (2017). Pengaruh Pelatihan Dan Motivasi Terhadap Kinerja Karyawan Dengan Disiplin Sebagai Variabel Intervening (Studi Kasus Di Fakultas Ekonomi Universitas Islam Indonesia). Upajiwa Dewantara, 1(2), 134-146. https://doi.org/10.26460/mmud.v1i2.1990 
Mubin, F., \& Masruri, A. (2020). Tipe dan Gaya Kepemimpinan. Artikel Ilmiah. https://doi.org/10.31219/osf.io/ntjy5.

Naranjo, J. (2014). Analisis Pengaruh Kepemimpinan Dan Motivasi Terhadap Komitmen Organisasi Dan Dampaknya Pada Kinerja Pegawai (Studi Kasus Pada Pegawai PT. Blue Bird Group Pool Daan Mogot). Applied Microbiology and Biotechnology, 85(1), 2071-2079. https://doi.org/10.1016/j.bbapap.2013.06.007

Nisyak, I. R. (2018). Pengaruh Gaya Kepemimpinan Dan Disiplin Kerja Terhadap Kinerja Karyawan (Sekolah Tinggi Ilmu Ekonomi Indonesia (STIESIA) Surabaya). AtTadbir : Jurnal Ilmiah Manajemen, 2(1). https://doi.org/10.31602/atd.v2i1.1189

Kirana, K. C. dan Ratnasari. R. T. (2017). Evaluasi Kinerja Sumber Daya Manusia. Yogyakarta: Gosyen Publishing.

Ratnasari, S. L., Sutjahjo, G., \& Yana, D. (2019). Leadership Style, Work Discipline, Compensation, Employee Performance Through Employee Motivation Bank Syariah X Branch Batam. Etikonomi, 18(1), 63-72. https://doi.org/10.15408/etk.v18i1.6752

Reza, R. A., \& Dirgantara, I. (2010). Pengaruh gaya kepemimpinan, motivasi dan disiplin kerja terhadap kinerja karyawan PT Sinar Santosa Perkasa Banjarnegara. Skripsi. Bachelor Programme. Semarang:Universitas Diponegoro.

Rotinsulu, J., \& Hartono, W. (2015). Pengaruh Gaya Kepemimpinan, Komunikasi Dan Pembagian Kerja Terhadap Kinerja Karyawan Pada Pt. Prima Inti Citra Rasa Manado. Jurnal Riset Ekonomi, Manajemen, Bisnis Dan Akuntansi, Vol.3 (2): https://doi.org/10.35794/emba.v3i2.9246

Setiawan, A. (2013). Pengaruh Disiplin Kerja Dan Motivasi Terhadap Kinerjakaryawan Pada Rumah Sakit Umum Daerah Kanjuruhan Malang. Jurnal Ilmu Manajemen (JIM), 1(4).

Ufua, D. E., Salau, O. P., Ikpefan, O., Dirisu, J. I., \& Okoh, E. E. (2020). Addressing operational complexities through re-inventing leadership style: A systemic leadership intervention. Heliyon, 6(7), e04270. https://doi.org/10.1016/j.heliyon.2020.e04270

Jurnal Manajemen (2020). Penilaian Kinerja Karyawan : Pengertian, Tujuan, Manfaat, dan Proses. Available at https://jurnalmanajemen.com/penilaian-kinerja-karyawan/ 